\title{
Intersection of Verbal Memory and Expressivity on Cortical Contrast and Thickness in First Episode Psychosis
}

\author{
Carolina Makowski ${ }^{\mathrm{a}, \mathrm{b}, \mathrm{c}, \mathrm{d}}$, John D. Lewis ${ }^{\mathrm{a}, \mathrm{b}, \mathrm{c}}$, Claude Lepage ${ }^{\mathrm{a}, \mathrm{b}, \mathrm{c}}$, Ashok K. Malla ${ }^{\mathrm{d}, \mathrm{e}}$, Ridha Joober ${ }^{\mathrm{d}, \mathrm{e}}$, \\ Alan C. Evans ${ }^{\mathrm{a}, \mathrm{b}, \mathrm{c} *}$, Martin Lepage $\mathrm{e}^{\mathrm{d}, \mathrm{e} *}$

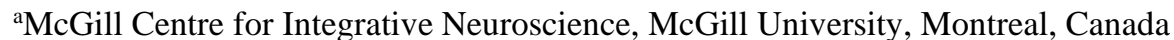

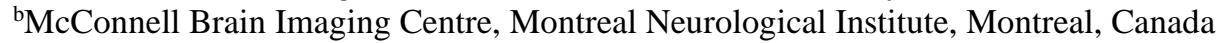 \\ 'Ludmer Centre for Neuroinformatics and Mental Health, Montreal, Canada \\ ${ }^{\mathrm{d} D e p a r t m e n t}$ of Psychiatry, McGill University, Verdun, Canada \\ ePrevention and Early Intervention Program for Psychosis, Douglas Mental Health University Institute, Verdun, \\ Canada \\ *Authors share senior authorship.
}

Running Title: Verbal Memory and Expressivity in Early Psychosis

Word Count: Abstract: 250, Body: 6045.

Figures: 3. Tables: 1 . Supplementary Material: 1.

\section{Corresponding Author:}

Martin Lepage, Douglas Mental Health University Institute, Verdun, QC, Canada H4H 1R3. Phone: 5147616131 ext. 4393. Email: martin.lepage@mcgill.ca.

C. Makowski; J. D. Lewis; C. Lepage; A. K. Malla; R. Joober; A. C. Evans; M. Lepage. 2020. Intersection of verbal memory and expressivity on cortical contrast and thickness in first episode psychosis. Psychol Med, 50(11). DOI: 10.1017/S0033291719002071 
Makowski et al., Verbal Memory and Expressivity in Early Psychosis

Originally Published at 10.1017/s0033291719002071

\section{Abstract}

Background: Longitudinal studies of first episode of psychosis (FEP) patients are critical to understand the dynamicity of clinical factors influencing functional outcomes; negative symptoms and verbal memory (VM) deficits are two such factors that remain a therapeutic challenge. This study uses white-gray matter contrast at the inner edge of the cortex, in addition to cortical thickness, to probe changes in microstructure and their relation with negative symptoms and possible intersections with verbal memory.

Methods: T1-weighted images and clinical data were collected longitudinally for patients $(\mathrm{N}=88)$ over a two-year period. Cognitive data were also collected at baseline. Relationships between baseline VM (immediate/delayed recall) and rate of change in two negative symptom dimensions, Amotivation and Expressivity, were assessed at the behavioural level, as well as at the level of brain structure.

Results: VM, particularly immediate recall, was significantly and positively associated with a steeper rate of Expressivity symptom decline ( $\mathrm{r}=0.32$, $\mathrm{q}=0.012)$. Significant interaction effects between baseline delayed recall and change in expressivity were uncovered in somatomotor regions bilaterally for both white-gray matter contrast and cortical thickness. Furthermore, interaction effects between immediate recall and change in expressivity on cortical thickness rates were uncovered across higher-order regions of the language processing network.

Conclusions: This study shows common neural correlates of language-related brain areas underlying Expressivity and VM in FEP, suggesting deficits in these domains may be more linked to speech production rather than general cognitive capacity. Together, white-gray matter contrast and cortical thickness may optimally inform clinical investigations aiming to capture peri-cortical microstructural changes. 


\section{Background}

Negative symptoms (e.g. amotivation, flattened affect) and cognitive impairments in individuals with psychotic disorders are strong predictors of poor functional outcome (Albert et al. 2011; Lepage et al. 2014), and are less responsive to currently available medications compared to positive symptoms (e.g. hallucinations, delusions). Verbal memory (VM) is one of the most strongly impacted of all cognitive domains in individuals with psychotic disorders (Jordan et al. 2014; Benoit et al. 2015; Guimond et al. 2016), and is linked to persistent negative symptoms (Hovington et al. 2013). There is some evidence suggesting that VM and negative symptoms, particularly deficits in communication or expressivity, may share common neural substrates. Cohen \& Elvevåg (2014) have suggested that expressivity is linked to classic language areas in psychiatric disorders, although such a relationship has not been demonstrated in early stages of psychosis with non-invasive imaging techniques.

Many studies treat VM and negative symptoms as unitary constructs, although these variables are comprised of stable subdomains that are likely to be of clinical relevance; for instance, VM can be broken down into verbal learning vs. retention, and negative symptoms into amotivation and expressivity, all of which have unique environmental and biological correlates (Malla et al. 2002; Leeson et al. 2009; Millan et al. 2014). For instance, different facets of VM have been differentially associated to white matter microstructure (typically assessed using metrics such as fractional anisotropy from diffusion-weighted imaging) in healthy older adults, where white matter tracts subserving left fronto-parietal regions are related to verbal working memory, whereas bilateral fronto-temporal white matter is linked to long-term episodic memory function (Charlton et al. 2013). Both grey and white matter abnormalities have been observed in relation to amotivation symptoms (e.g. avolition, apathy) in enduring schizophrenia patients, 
particularly decreased cortical thickness and fractional anisotropy underlying left orbital/medial frontal cortex and cingulate cortex (Ohtani et al. 2014; Mørch-Johnsen et al. 2015, 2018). A recent study has also shown that the integrity of white matter underlying the right hemisphere homologs of these regions is related to affective flattening (Ohtani et al. 2015); however, beyond this study, very few have further investigated the structural brain correlates of expressivity deficits (Mørch-Johnsen et al. 2018), especially in first episode of psychosis (FEP) patients. Importantly, and of relevance to the current study, longitudinal brain imaging studies of negative symptoms in FEP are scarce, although altered maturational trajectories of cortical thickness and limbic structure has been previously observed in patients with persistent negative symptoms (Makowski et al. 2016, 2017). Such longitudinal neuroimaging studies are critical to characterize the emergence of clinical, cognitive, and neuroanatomical markers that may be amenable to intervention early in the course of the disorder. Existing literature examining progressive brain changes after a FEP, irrespective of symptom profiles, have reported widespread accelerated gray matter loss (Andreasen et al. 2011; Gong et al. 2016). Various structural and functional MRI reviews of FEP patients have pinpointed progressive brain changes occurring across frontal and temporal lobes, particularly within the left hemisphere (Radua et al. 2012; Vita et al. 2012; Dazzan et al. 2015). Further, evidence suggests that the stability of medial temporal and prefrontal cortices may be essential predictors of symptomatic and functional outcomes after a first episode of schizophrenia (Dazzan et al. 2015).

White matter abnormalities have also been a key focus of studies of schizophrenia and related disorders, across different disease stages (Kubicki et al. 2005; Whitford et al. 2007, 2012; Carletti et al. 2012; Lee et al. 2013; Birur et al. 2017; Klauser et al. 2017; Kelly et al. 2018). Evidence from post-mortem studies and diffusion tensor imaging suggests that white matter 
abnormalities, particularly within prefrontal regions, are more significantly correlated with negative symptoms compared with positive symptoms (Uranova et al. 2011; Asami et al. 2014). Other neuroimaging studies have obtained proxy measures of myelin to better understand the nature of white matter alterations in psychosis (Andreasen et al. 1991; Lang et al. 2014; Ganzetti et al. 2015; Iwatani et al. 2015). There is certainly a need to shift focus to earlier stages of psychosis, obtaining measures more proximal to a FEP, to better understand the cascade of brain structural alterations that follow.

Although measures of cortical thickness (CT) are often the choice of methodology for investigation of cortical structure in psychiatric disorders from T1-weighted MRI scans, inconsistencies have arisen in a number of studies of longitudinal cortical thickness trajectories in early psychosis, with a handful of studies contesting the evidence of progressive brain change after a FEP (Nesvåg et al. 2012; Roiz-Santiáñez et al. 2015; Haukvik et al. 2016), emphasizing the need for novel approaches to analyze structural data in clinical cohorts. Obtaining a measure of white-gray matter contrast (WGC) from T1-weighted MRI may provide a meaningful marker of myelin content and other biophysical properties that may complement measures of cortical thickness (Salat et al. 2009; Westlye et al. 2009; Andrews et al. 2017; Lewis et al. 2018). We have recently shown that WGC captures brain architectural features and putative network-level abnormalities in FEP patients more robustly than measures of cortical thickness (Makowski et al. 2019). Thus, using multiple measures to assess the integrity of the cortical mantle, including a proxy measure of peri-cortical myelin, could provide a better understanding of the neurobiological correlates underlying subdomains of negative symptoms and VM, particularly in FEP patients. This is turn could be paramount in developing more effective treatments in early psychosis, and other disorders that are characterized by similar deficits. 
The aims of the current study were to i) examine the relationship between two negative symptom dimensions (Expressivity and Amotivation) and deficits in two VM processes (immediate and delayed recall), ii) relate Expressivity and Amotivation negative symptom dimensions to changes in CT and WGC across time, and iii) see how relationships in ii) interact with VM capacity. We expect Expressivity and Amotivation to be uniquely correlated with progressive changes in white-gray contrast, and to be moderated by VM abilities. Specifically, we postulate that immediate recall, a measure of verbal learning, will be more strongly correlated with Expressivity both at the levels of brain and behaviour, given that both constructs have been described as “core” traits in psychosis and less influenced by external factors (Leeson et al. 2009; Lutgens et al. 2014). On the other hand, we expect delayed recall, a measure of verbal retention, to be more related to Amotivation, due to these factors' higher potential to be influenced by environment.

\section{Methods}

\section{Sample.}

Patients were recruited from the Prevention and Early Intervention Program (PEPP) at the Douglas Institute in Montreal, Canada, and were part of a longitudinal naturalistic outcome study. Details are outlined elsewhere (Iyer et al. 2015). Inclusion criteria at PEPP include a diagnosis of affective (e.g. bipolar disorder, depression with psychotic features) or non-affective psychosis (e.g. schizophrenia, schizoaffective), an IQ above 70, and limited (<1month) to no previous exposure to antipsychotic medication. Patients recruited to PEPP (ages 18-35) were invited to take part in a neuroimaging study, comprising three timepoints (baseline, one/two-year follow-ups) as described in previous work (Makowski et al. 2016, 2017). Patients were recruited 
from February 2003 to February 2014. The first baseline scan took place in May 2004. It should be noted that many of the initial patients recruited for the study did not meet criteria for this neuroimaging investigation, as more than 6 months passed between entry to the PEPP clinic and their baseline scan. The last two-year follow-up scan and clinical assessment for the last patient took place in April 2016.

Non-clinical healthy controls were recruited through advertisements within the same local catchment area. All participants provided written informed consent, and the research protocol was approved by the Douglas Institute human ethics review board. From 150 FEP patients recruited for the study, 88 patients (Male, $\mathrm{N}=62$ ) were included in analysis. Data from 80 healthy controls were included for calculation of standardized VM scores, as described below. See Supplementary material for more detailed information on the final included sample and demographic/clinical data collection. Also see Supplementary Table 1 for a comparison of patients included in the study, compared to those who were excluded.

We opted to include both affective and non-affective psychoses in our sample of FEP patients, as our group has previously shown that clinical diagnoses play a negligible role in findings related to MRI-derived metrics, including cortical thickness (Makowski et al. 2016, 2017). Further, our aims are to investigate individual clinical/cognitive profiles, rather than work within a diagnostic framework, which is being recognized as a clear setback in the field of psychiatry (Insel et al. 2010; Owen 2018; Wolfers et al. 2018). However, we also explored differences in key variables of interest, namely immediate/delayed recall, and amotivation and expressivity deficits, between patients on the schizophrenia spectrum and patients with an affective disorder. No significant differences emerged between groups as can be seen in

\section{Supplementary Table 2.}




\section{Negative Symptom Dimensions and Change Over Time.}

Negative symptoms were assessed using the Scale for the Assessment of Negative Symptoms (SANS) (Andreasen 1984), which has been shown to have good inter-rater reliability $(\kappa=0.71)$ at PEPP-Montreal (Jordan et al. 2018). Item-level scores from the SANS were used to define two principal dimensions of negative symptoms: Amotivation and (lack of) Expressivity. These dimensions were based on a consistent body of literature reporting a two-factor model of negative symptoms (Malla et al. 2002; Blanchard \& Cohen 2006; Kirkpatrick et al. 2006; Messinger et al. 2011; Jang et al. 2016; Marder \& Galderisi 2017). Items were assigned to either the Amotivation or Expressivity dimension based on a recent confirmatory factor analysis published by our group (Lutgens et al. 2019). Although other models have been proposed to categorize negative symptoms, for instance a recent investigation uncovering a 5-factor latent structure of negative symptoms in schizophrenia (Strauss et al. 2018), it is important not to dismiss a large breadth of literature that has linked motivation and expressivity dimensions of negative symptoms to functional outcomes in patients. Finally, a two-factor solution minimizes the burden of multiple comparisons and potential false positives for the purposes of our neuroimaging analysis.

Thus, based on Lutgens et al (2019), Amotivation in this study represented summed items from "Avolition-Apathy” and "Anhedonia-Asociality” domains, while the Expressivity dimension represented summed items from “Affective Flattening/Blunting” and “Alogia” domains, excluding Item 6: “Inappropriate Affect” and Item 10: “Poverty of Content of Thought”, given that these items do not effectively map onto the clinical construct of Expressivity (Lutgens et al. 2019). To assess the mean rate of change in symptoms over time, a linear model was fit to each 
subject's longitudinal amotivation and expressivity symptom data against the participants' age over all available timepoints for that participant. A slope was calculated and extracted for each subject to represent a single metric of change over time in symptoms.

\section{Verbal Memory Performance.}

VM data were collected from a larger neuropsychological battery database for patients followed at PEPP. Due to a change in neuropsychological testing protocol, VM data were compiled from two different protocols: 1) a pen and paper format administered to patients who took part in the study from 2003 to 2010, using Logical Memory subtests of the Wechsler Memory Scale-Third Edition (WMS-III) (Wechsler 1997); and 2) the CogState Research Battery (Pietrzak et al. 2009), administered from September 2010 onwards, using the International Shopping List task. Further details of both testing protocols and tasks have been described before (Benoit et al. 2015). Z-scores were calculated for each neuropsychological test battery separately, using the mean and standard deviation of controls for immediate/delayed recall measures. Previous work from our group (Benoit et al. 2015) has shown that participants tested with the CogState Research Battery tended to perform better. Thus, in addition to using standardized scores, test version was used as a covariate in analyses using VM data. Supplementary Table 3 demonstrates there are no significant version or group*version effects on verbal memory performance.

\section{MRI acquisition.}

Scans were collected at the Montreal Neurological Institute, all on the same 1.5-Tesla Siemens Sonata MRI scanner. Structural T1-weighted volumes were acquired for each participant using a 
3D gradient echo pulse sequence with sagittal volume excitation (resolution $=1 \mathrm{~mm}^{3}$, repetition time $=22 \mathrm{~ms}$, echo time $=9.2 \mathrm{~ms}$, flip angle $=30^{\circ}, 1801 \mathrm{~mm}$ contiguous sagittal slices). The rectangular field of view (FOV) for the images was 256mm (AP) 204mm (SI).

\section{MRI Post-Processing.}

Cortical Thickness. Raw T1-weighted images were submitted to the CIVET pipeline (Version 2.1.0: http://www.bic.mni.mcgill.ca/ServicesSoftware/CIVET) (June et al. 2005) for extraction of gray and white matter surfaces. Main processing steps include: 1) Registration of T1weighted images to standardized space (Collins et al. 1994) and correction for non-uniformity artefacts (Sled et al. 1998); 2) segmentation of gray, subcortical gray and white matter, and cerebral spinal fluid (Zijdenbos et al. 2002; Tohka et al. 2004); 3) extraction of the white matter surface using a marching-cubes algorithm and extraction of the gray matter surface using the CLASP algorithm (Kim et al. 2005); 4) surface registration to a template for intersubject correspondence (Lyttelton et al. 2007); 5) reverse transformation (initially done in step 1) to estimate CT in native space for each subject at 81,924 vertices using the t-laplace metric (Lerch \& Evans 2005); and 6) smoothing the data in native space with a 20mm FWHM Gaussian kernel to diminish the impact of noise (Boucher et al. 2009). CT was estimated using the Laplacian distance between the two surfaces (Jones et al. 2000) across 81,924 vertices.

White-Gray Matter Contrast. Measures of WGC were generated as follows, similarly to what is described in Makowski et al (2019): 1) additional surfaces were created 1mm on either side of the surface at the gray-white matter boundary (i.e. $+1 \mathrm{~mm}$ corresponds to supra-white surface, and -1mm corresponds to sub-white surface); 2) surface maps of the intensity of the T1-weighted 
MRI were generated and smoothed; and 3) a ratio was calculated, by dividing the intensity of the -1mm point by the corresponding $+1 \mathrm{~mm}$ point, as defined by Lewis et al (2018). WGC values ranged from approximately 1.15 to 1.35 where lower values, closer to 1 , reflect lower contrast (i.e. reduced gray-white matter distinction) whereas higher values reflect higher contrast (i.e. clearer distinction between gray and white matter). The WGC method is depicted in Figure 1. More details of imaging methods and quality control procedures are outlined in Supplementary Material.

\section{Statistical Analyses of Behavioural/Clinical Data.}

Demographic and clinical variables were analysed with one-way ANOVAs for continuous variables or Kruskall-Wallis $\mathrm{H}$ tests for nominal variables. An ANCOVA was used to analyse differences in VM performance at baseline between patients and controls, covarying for test version and years of education. Additional tests to compare the effect of version on results with VM data, as well as exploratory analyses between change in negative symptoms and change in verbal memory scores for a subset of patients with longitudinal data available $(\mathrm{N}=49)$, are in Supplementary material. Associations between rates of change in Amotivation/Expressivity negative symptom domains and immediate/delayed recall in FEP patients were evaluated with Pearson r-correlations, adjusting verbal memory values for age, sex, and test version, and taking into account multiple comparisons with a false discovery rate (FDR) correction (Benjamini \& Hochberg 1995). Analyses of behavioural and clinical variables were conducted using PASW Statistics 21 (SPSS inc., 2009, Chicago, IL, USA) and were two-tailed with a critical $p$-value of 0.05. Normality of continuous data was assessed with the Shapiro-Wilk test of normality. Nonparametric tests were used to compare demographic variables between patients and controls that 
were found not to be normally distributed. Demographic and clinical information was also compared between patients included in this manuscript $(\mathrm{N}=88)$ and patients excluded from the study ( $\mathrm{N}=47$ ) despite meeting criteria for a FEP, due to the cross-sectional nature of their data and/or failed imaging data after QC.

\section{Surface-Based Brain Analyses.}

Vertex-wise analysis of WGC and CT were conducted using SurfStat in Matlab

(http://www.math.mcgill.ca/keith/surfstat/). As with the negative symptom data and as described in Raznahan et al (2011), a linear model was fit to each vertex for the WGC and CT data, yielding a single metric for each subject describing the rate of change in years in WGC and CT. To determine which covariates should be used for analyses, the Akaike Information Criterion (Akaike 1998) was used to determine the best model. AIC values were compared to a 'baseline' model that included centered age and sex as covariates, given the well-documented impact of age and sex on neuroanatomy, as well as their influence on the onset and progression of psychosis (Tamnes et al. 2010; Ochoa et al. 2012; Makowski et al. 2016, 2017) . Details are included in the Supplementary material, including an analysis testing the effect of antipsychotic medication on WGC and CT (Supplementary Figure 1) and justification on the exclusion of medication as a covariate.

The following model was used to assess the main effect of change in negative symptoms ( $\eta$, representing either amotivation or expressivity deficits) on change in $\mathrm{Y}$ (representing either WGC or CT), covarying for centered age, sex, and mean $\sigma$ (reflecting mean WGC or mean CT across the entire cortical surface for each participant): $\Delta Y=$ intercept $+\beta_{1}(\Delta \eta)+\beta_{2}($ CenteredAge $)+\beta_{3}(\operatorname{Sex})+\beta_{4}(\operatorname{Mean}(\sigma))+\varepsilon$ 
Here, $\beta_{1}$ is the slope for the main effect of interest, namely, rate of change $(\Delta)$ in negative symptoms per year. Note, $\beta_{2}$ and $\beta_{4}$ reflect measures at baseline. Positive values of the rate of $Y$ change reflect an increase in either WGC and CT per year, whereas positive values in negative symptom reflect an increase (i.e. worsening) in symptoms per year.

The interaction between baseline VM abilities ( $v$, reflecting Immediate Recall or Delayed Recall) and change in negative symptoms over time ( $\eta)$ on rate of change in WGC and CT ( $\Delta \mathrm{Y})$ was tested with the following model:

$\Delta Y=$ intercept $+\beta_{1}(\Delta \eta)+\beta_{2}(v)+\beta_{3}($ TestVersion $)+\beta_{4}($ Centered Age $)+\beta_{5}($ Sex $)+\beta_{6}(\operatorname{Mean}(\sigma))+\beta_{7}(\Delta \eta * v)+\varepsilon$ where $\beta_{7}\left(\Delta \eta^{*} v\right)$ represented the slope for the main predictor of interest; that is, the interaction between change in negative symptoms and baseline verbal memory. Here, $\beta_{2}, \beta_{3}, \beta_{4}$ and $\beta_{6}$ were measures taken at baseline. For visualization purposes only, patients were divided using a median split into two groups, on the basis of their verbal memory performance: "mild to moderate VM deficits" and "high VM deficits". Specific details of these groups are outlined in the Results section.

Random field theory (RFT) (Worsley et al. 2004) was used for multiple comparison correction using a stringent $\mathrm{p}$-cluster threshold of $\mathrm{p}=0.001$. Significant results are also presented with a more liberal cluster threshold of $\mathrm{p}=0.01$ ( $\mathrm{p}$-corrected $<0.05$ ), to show the extent of subthreshold results. For all significant clusters found with the more stringent cluster threshold ( $\mathrm{p}=0.001$ ), the WGC and CT, or rate of change in WGC and CT, at the peak t-statistic was extracted and adjusted for centered age, sex, and Mean $(\sigma)$, and used to generate scatterplots to visualize results. 
Makowski et al., Verbal Memory and Expressivity in Early Psychosis

Originally Published at 10.1017/s0033291719002071

\section{Results}

The final sample comprised 88 FEP patients, of which 59 patients completed all three scans, and the remainder had two scans. See Table 1 for descriptive statistics and clinical information. Importantly, FEP patients had a median duration of untreated psychosis of approximately 20 weeks, highlighting the efforts that have been put forth by the PEPP-clinic to minimize patients' pathways to care within our early intervention service (Iyer et al. 2015; MacDonald et al. 2018). This also emphasizes that our FEP patients are indeed highly representative of the first-episode time period. Included patients were also compared to 47 patients that were excluded from the current study on variables collected at baseline, and these results can be found in Supplementary Table 1. In summary, included patients did not differ largely from the excluded patients, except included patients had longer duration of untreated psychosis and untreated illness compared to excluded patients.

Summary statistics for rate of change in negative symptoms domains for 88 FEP patients with longitudinal data were as follows: Mean $\Delta$ Amotivation=-1.80 (SD=4.22 Range=-11.72 13.61), Mean $\Delta$ Expressivity=-1.22 ( $\mathrm{SD}=5.19$ Range=-19.63 - 14.66). For amotivation symptoms, 5 patients had the same level (or absence) of symptoms over time (Mean $\Delta=-0.0038, \mathrm{SD}=0.0086$ ), 25 patients had worsening symptoms (Mean $\Delta=3.12, \mathrm{SD}=2.91$ ), and 58 patients improved (Mean $\Delta=-4.08, \mathrm{SD}=2.72$ ). For expressivity symptoms, 16 patients had the same level (or absence) of symptoms over time (Mean $\Delta=0, \mathrm{SD}=0$ ), 22 patients had worsening symptoms (Mean $\Delta=4.64, \mathrm{SD}=4.02$ ), and 50 patients improved (Mean $\Delta=-4.18, \mathrm{SD}=4.01)$. See Supplementary Figure 2 for spread of longitudinal Amotivation and Expressivity negative symptom data. 
Makowski et al., Verbal Memory and Expressivity in Early Psychosis Originally Published at 10.1017/s0033291719002071

Relationship between Verbal Memory and $\Delta$ Negative Symptoms.

Cross-sectional relationships between VM and negative symptoms at baseline are reported in Supplementary material, where significant negative associations between baseline expressivity and immediate recall $(\mathrm{r}=-0.35, \mathrm{q}<0.001)$ and delayed recall $(\mathrm{r}=-0.28, \mathrm{q}=0.036)$ were found; no relationships were found with amotivation. The relationship between VM (i.e. z-scores of immediate and delayed recall) at baseline and $\Delta$ Negative Symptoms was assessed in 87 patients (degrees of freedom=82), for which baseline VM and longitudinal negative symptom data were available, using Pearson r correlations, adjusting verbal memory data for age, sex, and test battery. The only significant finding that survived FDR correction for multiple comparisons was a positive relationship between immediate recall at baseline and $\Delta$ Expressivity $(\mathrm{r}=0.32$, $\mathrm{q}=0.012$ ). In other words, better VM (i.e. less severe deficits) at baseline was associated with worsening Expressivity deficits over time. A trend-like association in the same direction was also found between delayed recall and $\Delta$ Expressivity ( $r=0.19$, $\mathrm{p}$-uncorrected $=0.083)$. No significant associations were found with either immediate or delayed recall and $\Delta$ Amotivation (Immediate: $r=0.079, \mathrm{q}=0.476$; Delayed: $r=0.077, \mathrm{q}=0.486$ ). Finally, we assessed the relationship between change in VM and change in negative symptoms over the first year after a FEP for a subset of patients ( $\mathrm{N}=49)$ for which data were available. No significant relationships were found, as reported in Supplementary Material.

\section{Associations between $\triangle$ Negative Symptoms and $\triangle W G C$ and $\triangle C T$.}

Worsening of Amotivation symptoms was associated with greater increases in WGC over time within the left superior parietal lobule and right dorsal primary motor cortex and paracentral lobule. Overlapping findings were found with respect to $\Delta$ Expressivity, with additional peaks in 
the left dorsal precentral gyrus and right cuneus. With respect to CT, $\Delta$ Expressivity was negatively associated with $\Delta \mathrm{CT}$ (i.e. cortical thinning with worsening symptoms) within left frontal regions. $\Delta$ Amotivation was not found to be significantly associated with changes in CT. Results are shown in Figure 2, along with the brain regions that survived correction for multiple comparisons with a relaxed $\mathrm{p}$-cluster threshold of $\mathrm{p}=0.01$. Plots were generated for regions that survived correction for multiple comparison with a stringent threshold of $\mathrm{p}<0.001$.

\section{Interaction between Verbal Memory and $\triangle$ Expressivity on $\triangle W G C$ and $\triangle C T$.}

Given that no significant associations were found between verbal memory and $\Delta$ Amotivation at the behavioural level, we did not explore this contrast. No significant regions survived the stringent threshold for WGC, however results with a relaxed threshold are in Figure 3. For CT, both immediate and delayed recall interacted significantly and uniquely with changes in Expressivity. The interaction between immediate recall and $\Delta$ Expressivity was significantly associated with changes in thickness along the left hemisphere ventrally, including the left orbital and medial frontal, insular, temporal pole, and middle temporal regions. The interaction term between delayed recall and $\Delta$ Expressivity showed significant effects on the right cuneus/primary visual cortex. Results are shown in Figure 3, along with brain regions that survived correction for multiple comparisons with a relaxed $p$-cluster threshold of $p=0.01$. Plots were generated for regions that survived correction for multiple comparison with a stringent threshold of $\mathrm{p}<0.001$. Even though no results survived correction for multiple comparisons with WGC with our stringent threshold, we also generated two additional plots with WGC data for right retrosplenial cortex and left central sulcus, to compare the nature of the associations against CT data.

To better visualize the direction of results, patients were divided into two groups based 
on their verbal memory performance using a median split, as described in the methods.

Specifically, the groups were broken down as follows: "mild to moderate VM deficits" ( $N=43$;

for immediate recall patients had a z-score higher than -1.15; for delayed recall, patients had a zscore higher than -0.91) and "high VM deficit" ( $\mathrm{N}=44$; for immediate recall, patients had a $\mathrm{z}$ score lower than or equal to -1.15; for delayed recall, patients had a z-score lower than or equal to -0.91). Note, one patient had missing verbal memory data at baseline, thus 87 patients were included in this analysis. Visualization of these groups generally revealed that patients with mild to moderate VM deficits (i.e. more preserved VM ability) at baseline drove the positive association between changes in expressivity symptoms and changes in WGC. For CT, patients with mild to moderate VM deficits at baseline predominantly drove the negative association between changes in expressivity and changes in thickness (Figure 3).

Results were also generated excluding mean $(\sigma)$ as a covariate; results were largely similar (Supplementary Figure 3). To ensure results in the final analysis were specific to verbal memory, a general cognitive index was calculated across five domains (i.e. attention, executive function, speed of processing, working memory, visual memory) and controlled for in analyses, yielding similar results (Supplementary Figure 4). Additional methods pertaining to cognitive data can be found in captions of Supplementary Figure 4/Supplementary Table 3.

\section{DISCUSSION/CONCLUSIONS}

These results provide insight into the relationship between surface-based brain metrics and two behavioural domains that contribute strongly to outcome in FEP patients, namely negative symptoms and VM. Two novel findings emerged: 1) rate of change in expressivity and amotivation negative symptoms over the two-year period following a FEP are associated with 
both overlapping and distinct changes in WGC, and are also associated with changes in left prefrontal regions in relation to CT; and 2) links between baseline VM and change in expressivity deficits are found both at the behavioural and neuroanatomical level, where significant interactions on rate of change over time in neuroanatomy were uncovered, most pronounced with CT.

We also extend a key finding of cortical thinning of the prefrontal cortex in relation to negative symptoms in psychosis (Galderisi et al. 2015; Walton et al. 2017), a finding that supports long-standing evidence that the frontal lobes are key contributors underlying negative symptom severity (Turetsky et al. 1995; Wible et al. 2001). Importantly, our findings suggest thinning is more specific to changes in Expressivity over a one to two year period. However, no associations were uncovered in the prefrontal cortex when examining WGC and negative symptom progression, suggesting these cortical thinning patterns may be due to neuroanatomical changes within more superficial layers. This idea is supported by several studies that cortical thinning of superficial layers as a key biological mechanism underlying altered neuroanatomy of the prefrontal cortex in schizophrenia (Wagstyl et al. 2016; Lake et al. 2017). Significant associations still emerged between expressivity deficits and WGC, but within primary sensory and motor regions. Similar patterns were uncovered with amotivation. We have previously shown that WGC of primary sensory and motor regions is related to general psychopathology in FEP patients (Makowski et al. 2019), and may be related to alterations within the high levels of intracortical myelin that typically characterize these regions (Glasser \& Van Essen 2011). It is possible that the association between contrast changes in primary sensory and motor regions and negative symptom severity is not specific to negative symptoms, but could also be related to general positive symptoms and cognitive deficits more generally. Although there are few studies 
that have looked at the neural correlates of expressivity and amotivation separately, one of the key regions that has emerged in several investigations is that of the association between avolition and activation of the striatum (Galderisi et al. 2015). Given our conjecture of WGC as a proxy measure of peri-cortical myelin, putatively tapping into integrity of cortico-cortical and corticosubcortical connections, it is interesting to consider this finding in light of potential aberrancies between cortico-striatal circuitry (Haber 2016).

A key discovery in our behavioural findings was the stronger association between VM specifically with Expressivity, as opposed to both negative symptom dimensions. Consistent with previous literature, we uncovered a negative association between VM performance and negative symptoms in psychosis cross-sectionally (Hartmann-Riemer et al., 2015). However, when assessing baseline VM performance against rate of change in symptoms, we identified a relationship that, at first glance, runs counter to intuition. Namely, it was found that patients with better VM at baseline (i.e. a mild level of VM deficits, particularly with immediate recall) had worsening of Expressivity symptoms, a relationship that has largely been unexplored longitudinally in psychosis. Our results suggest that having less striking VM deficits at intake does not necessarily protect against progressive changes in Expressivity. Other key cognitive factors, such as insight, may also contribute to this relationship. Based on previously identified positive relationships between cognitive insight and VM (Lysaker et al. 2005; Lepage et al. 2008), we can consider that patients with a better ability to recall stored information are also likely to have lower self-certainty and more self-reflectiveness (a profile that characterizes high levels of cognitive insight), which could set the stage for a trajectory of worsening Expressivity as the patient internalizes their mental illness. It is also important to note that many of the patients included in this study had an improving course of negative symptoms after the first two 
years after a FEP, consistent with a previous study (Lutgens et al. 2019). In this context, several studies have suggested that negative symptoms can improve in the absence of any change in verbal memory performance (Nopoulos et al. 1994; Cantor-Graae et al. 1995; Hoff et al. 1999). In a related vein, we also conducted a supplementary analysis exploring the potential relationship between change in verbal memory and change in negative symptoms over the first year after a FEP, for a subset of patients ( $\mathrm{N}=49$ ) for which data were available. No significant association was found, consistent with the studies cited above, but it is still possible that more timepoints would be needed to elucidate such longitudinal relationships. Many studies have suggested that cognition, including verbal memory, is a set of static traits, as suggested by evidence showing stability of cognitive performance from the clinical high risk state to transition to psychosis (Green \& Harvey 2014; Carrión et al. 2015). However, future studies are encouraged to further investigate longitudinal cognition-symptom relationships after psychosis onset; a future direction that our group is currently investigating as well.

It is also worth discussing the granularity of results with respect to immediate vs. delayed recall in relation to Expressivity. It has been shown that immediate recall is highly related to performance on other measures of cognition in schizophrenia (Leeson et al. 2009). Immediate recall may also have a stronger biological and/or genetic predisposition; deficits in immediate recall predict conversion to psychosis (Lindgren et al. 2017) and are present in non-affected siblings of schizophrenia twins (Goldberg et al. 1993). Together, this suggests that immediate recall may be a more "hard-coded" feature of psychosis compared to retention of information (i.e. delayed recall), with stronger biological and genetic influences. Further, Expressivity has also been recently posited to be a more primary negative symptom domain, and less influenced by environmental factors, such as community resources, compared to Amotivation (Lutgens et 
al. 2019). Our data present a feasible model whereby Expressivity and immediate recall or verbal learning may share common etiology and a potential endophenotype of interest for future studies.

More preserved immediate recall abilities contributed to the relationship between worsening of Expressivity deficits and cortical thinning across higher order language processing areas in ventral frontal areas and middle/inferior temporal gyri of the left hemisphere, which contributes to the semantic encoding of language (Saur et al. 2008) and for keeping verbal information active in working memory (Smith \& Jonides 1999). These areas are subserved by white matter tracts such as the uncinate and superior longitudinal fasciculi (Friederici 2011), which have been shown to be disrupted in schizophrenia patients with predominant negative symptoms (Sigmundsson et al. 2001). With WGC, an interesting relationship also emerged between expressivity deficits and increases in contrast between patients with different levels of immediate recall performance within the retrosplenial cortex bilaterally. Although these results were only significant with a relaxed threshold when correcting for multiple comparisons, the retrosplenial cortex is interesting to consider in this context as it is a region that has been strongly linked to memory function (Vann et al. 2009), as well as more recently, to the reinforcement of salient behavioural cues (Smith et al. 2012, 2018), which is likely to contribute during immediate learning phases of memory. A previous study has also shown that white matter volume abnormalities exist within the retrosplenial cortex in schizophrenia patients (Mitelman et al. 2005).

Meanwhile, the interaction between delayed recall and expressivity uncovered regions of the dorsal language processing stream, namely superior parietal lobule, dorsal primary somatomotor and premotor areas, which relates more to language production (Saur et al. 2008). 
Disruptions in these cortical regions could plausibly support a mechanistic explanation of the lowered rate of speech production and/or increased psychomotor retardation observed in patients with expressivity deficits (Cohen et al. 2014; Marder \& Galderisi 2017), as well as the necessity for preserved structure/function of the left posterior dorsolateral prefrontal cortex in delayed retrieval (Alexander et al. 2003). Our results also did not change when accounting for a general cognitive index that comprised five cognitive domains. Together, these results suggest that the relationship between Expressivity deficits and VM may be more closely linked to speech articulation or language production mechanisms, as opposed to general cognitive abilities.

It is worth noting that WGC and CT are related metrics, but they also tap into different neurobiological properties (Westlye et al. 2009). WGC may take myelination patterns into account more strongly than CT, and may shed light on a compartment of the cortex that may be more amenable to short-term changes (Wenger et al. 2017), which in turn may be a more viable biomarker target in FEP patient samples as measured on MRI.

Several limitations should be considered. Our model did not capture patients who had a consistently high or low level of negative symptoms, as well as the distinction between primary and secondary negative symptoms. These individual patterns of negative symptoms have been touched upon by some of our previous work (Makowski et al. 2016, 2017), but future investigations are encouraged to parse apart such trajectories in myelin and/or other microstructural compartments. The rates of change in both cortical metrics and negative symptoms should also be interpreted as a proxy measure of negative symptom/cortical change, as subtle non-linear fluctuations over time are not captured by the measures presented in this manuscript. Limitations in accurately and objectively assessing negative symptoms should also be considered, where rater bias may preclude the treatment of Amotivation and Expressivity as 
completely independent domains. Automated unbiased assessments of negative symptoms, such as software that has been developed to assess communication deficits and natural language in patients with schizophrenia (Cohen \& Elvevåg 2014), may provide data with higher construct validity in this respect. It should also be noted that many patients ultimately showed an improvement in negative symptoms; although this improvement has been reported before in the first two years after a FEP (Lutgens et al. 2019), we cannot rule out that patients with improvement in negative symptoms ultimately comprise a subset of patients that are more motivated to participate in longitudinal studies such as the one described here. With respect to cognitive data, we collected VM from two batteries, although examination of the tests and standardization of our data suggests test version likely did not significantly impact our findings. Our VM data was also limited by the fact that it was largely cross-sectional; as mentioned, future studies would benefit from studying potential temporal changes in such cognitive performance after a FEP. Finally, although our patient sample was largely antipsychotic-naïve at the beginning of the study, many of these patients were prescribed antipsychotic medications. Our exploration of antipsychotic medication on rate of change in WGC and CT showed no notable effect, however individual medication classes could have differential effects on gray/white matter (Bartzokis et al. 2009; Szeszko et al. 2014; Abramovic et al. 2016).

Although further work is needed to clarify the longitudinal relationships between cognition and negative symptoms, this avenue is promising in understanding domains of psychosis which have largely gone untreated. These findings may also hold implications for other neurological and psychiatric disorders characterized by negative symptom presentation and verbal memory deficits. Given that structural MRI is one of the most commonly used imaging 
techniques in psychiatric neuroimaging studies, extracting WGC and CT together may be fruitful in the broader search for a valid and easy-to-measure biomarker in psychiatry.

Acknowledgments. We would like to thank PEPP-Montreal and Lepage Lab research staff for their efforts in recruitment and clinical data collection. We are also grateful to all patients and families for participating in the study.

Conflict of Interest Disclosures. A.C.E. has received consulting fees from Biospective. M.L. reports grants from Otsuka Lundbeck Alliance, personal fees from Otsuka Canada, personal fees from Lundbeck Canada, grants and personal fees from Janssen, and personal fees from MedAvante-Prophase, outside the submitted work. R.J. reports receipt of grants, speaker's fees, or honoraria from AstraZeneca, BMS, Janssen, Lundbeck, Otsuka, Pfizer Canada, Shire, and Sunovion and royalties from Henry Stewart Talks. A.M. reports receipt of grants, fees, or honoraria from BMS, Lundbeck, and Otsuka. The authors have no other competing interests to disclose.

Funding/support. The study was supported by operating grants from the Canadian Institutes of Health Research (CIHR, 68961, MCT-94189); the Fonds de Recherche du Quebec - Santé (FRSQ); Sackler Foundation; and by grant ANRP-MIRI13-3388 from the Azrieli Neurodevelopmental Research Program in partnership with the Brain Canada MultiInvestigator Research Initiative (to A.C.E.). It also benefited from computational resources 
provided by Compute Canada (www.computecanada.ca) and Calcul Quebec

(www.calculquebec.ca). Salary awards include: Canadian Institutes for Health Research

(CIHR; C.M., R.J., M.L., A.C.E.), Fonds de la Recherche en Santé du Québec (FRSQ; C.M., M.L., and R.J.), funding from the Canada First Research Excellence Fund, awarded to McGill University for the Healthy Brains for Healthy Lives Initiative (C.M., A.C.E.), James McGill Professorship (M.L., A.C.E.) and Canada Research Chairs Programme (A.K.M.).

Role of the Funder/Sponsor: The funding organizations had no role in the design and conduct of the study; collection, management, analysis, and interpretation of the data; preparation, review, or approval of the manuscript; and decision to submit the manuscript for publication. 
Makowski et al., Verbal Memory and Expressivity in Early Psychosis

Originally Published at 10.1017/s0033291719002071

\section{FIGURE AND TABLE CAPTIONS}

Table 1. Demographic and clinical information. General Demographics for whole sample are presented, followed by information corresponding to each scan. All data represented as Mean (SD), unless otherwise specified. Square brackets [] include adjusted sample size included in statistical analysis due to missing datapoints. All antipsychotic totals are presented as cumulative chlorpromazine equivalents in mg (i.e. a composite measure of the total amount of antipsychotic medication prescribed during the entire study), as prescribed by a psychiatrist, and are reported along with a percentage of medication adherence. SAPS totals are presented as mean scores of the sum of item-level scores. Duration of untreated psychosis and illness reflect length of time between onset of psychotic symptoms and onset of other psychiatric symptoms until initiation of antipsychotic medication treatment, respectively. Further details on collection of clinical data can be found in Supplementary Methods (section ii). Years of education, socioeconomic status, performance and verbal IQ were found to be non-normally distributed; thus, non-parametric tests to compare group means were used.

*FEP patients had significantly lower levels of verbal memory performance (immediate/delayed recall), lower performance and verbal IQ, and less years of education compared to $\mathrm{HC}(\mathrm{p}<0.05)$.

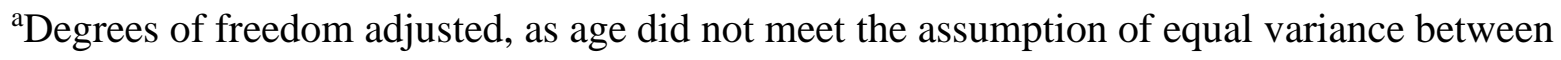
groups as assessed with Levene’s test.

${ }^{\mathrm{b} C o v a r i e d}$ by test version. Specifically, IQ was collected with WAIS-III and WASI (more details in Supplementary Material), and verbal memory was collected with a Pen and Paper neuropsychological test battery, and CogState Research Battery. 
Makowski et al., Verbal Memory and Expressivity in Early Psychosis

Originally Published at 10.1017/s0033291719002071

${ }^{\mathrm{c}}$ Note, Mean and Standard Deviation of Verbal Memory in Controls does not equate to exactly 0 and 1 , respectively, as the norms for verbal memory were calculated before exclusion of a subset of controls for this study due to imaging quality control.

Abbreviations: CDSS, Calgary Depression Scale for Schizophrenia. CPZ, chlorpromazine. FEP, First Episode of Psychosis. FUP, follow-up. SAPS, Scale for Assessment of Positive Symptoms. 
Figure 1. White-gray matter contrast method. Illustration of 3 key steps in calculation of WGC, as described in the main manuscripts. Method was initially presented in Lewis et al (2018) (Lewis et al. 2018) and also applied by our group recently to a cross-sectional FEP cohort (Makowski et al. 2019). Left-hand panel is an example of a T1-weighted image from a participant included in the study, with the gray-white matter boundary and $+/-1 \mathrm{~mm}$ surfaces overlaid, as defined in Step i. Surfaces maps of the intensity of the T1-weighted MRI were then generated and smoothed with a 20mm blurring kernel (Step ii). Smoothing is done for both the -1 and $+1 \mathrm{~mm}$ surfaces before calculation of WGC (Step iii). One example vertex is identified to illustrate calculation of WGC (Step iii). Note, in some areas the surfaces do not appear to be consistently $1 \mathrm{~mm}$ from the gray-white matter boundary; this is because a $2 \mathrm{D}$ visualization of the surfaces is depicted here, without taking into consideration the third dimension of the T1weighted image.

\section{Figure 2. Change in Amotivation and Expressivity deficits associated with change in}

WGC/CT across time. Results are RFT-corrected, where blue colours represent significant results cluster-thresholded at a "stringent" threshold of $\mathrm{p}=0.001$, whereas red/pink colour represent significant results at a "relaxed" threshold of $\mathrm{p}=0.01$. Selected regions for scatterplots are those that survived multiple comparisons with the more stringent cluster threshold of $\mathrm{p}=0.001$. Plots with Amotivation are plotted with a dotted line and crosses, whereas Expressivity data are plotted with a solid line and circular markers. For overlapping cluster within right paracentral gyrus of the effect of negative symptoms on WGC (top two rows), a common peak was selected where amotivation and expressivity are included on the same plot. Abbreviations: SPL, Superior Parietal Lobule. 
Orientation: Surfaces from left to right in each row: left lateral, right lateral, left medial, right medial, dorsal.

Figure 3. Interaction between baseline verbal memory and change in Expressivity on WGC and CT. Results are RFT-corrected, where blue colours represent significant results clusterthresholded at "original" stringent threshold of $\mathrm{p}=0.001$, whereas red/pink colour represent significant results at a "relaxed" threshold of p=0.01. "Immediate" and "Delayed" labels of lefthand side panel refer to immediate and delayed recall of verbal memory domain, respectively. Inflated brain is presented to better visualize results within cortical folds. Selected regions for scatterplots are those that survived multiple comparisons with the more stringent cluster threshold of $\mathrm{p}=0.001$ for cortical thickness data. Although nothing survived correction after stringent correction for WGC analyses, peaks within left central sulcus and right retrosplenial cortex were plotted to explore the direction of results with WGC. To better visualize the interaction effect of two continuous variables (rate of change in expressivity and baseline VM), patients were divided based on low/moderate VM deficit (purple) and high VM deficit (yellow). Plots separating patients on the basis of immediate recall are depicted with crosses, and delayed recall with diamonds. Orientation: Surfaces from left to right in each row: left lateral, right lateral, left medial, right medial, dorsal (with the exception of the third row, where the last surface is a ventral view). 
Makowski et al., Verbal Memory and Expressivity in Early Psychosis

Originally Published at 10.1017/s0033291719002071

Table 1.

\begin{tabular}{|c|c|c|c|c|c|}
\hline & $\begin{array}{c}\text { FEP } \\
N=88\end{array}$ & $\begin{array}{c}\text { Controls } \\
\mathbf{N}=\mathbf{8 0}\end{array}$ & & & \\
\hline & \multicolumn{2}{|c|}{ N (\%) } & Statistic & df & p-value \\
\hline Male & $62(70)$ & $52(65)$ & $\chi^{2}=0.57$ & 1 & 0.51 \\
\hline Right Handed & $73(83)$ & $73(91)$ & $\chi^{2}=2.53$ & 1 & 0.17 \\
\hline \multicolumn{6}{|l|}{ Diagnosis } \\
\hline Schizophrenia/ Schizophreniform & $63(72)$ & & & & \\
\hline Affective Disorder & $16(18)$ & & & & \\
\hline Delusional Disorder & $3(3)$ & & & & \\
\hline Psychosis Not Otherwise Specified & $6(7)$ & & & & \\
\hline
\end{tabular}

General Demographics

\begin{tabular}{|c|c|c|}
\hline \multirow{11}{*}{$\begin{array}{c}\text { General } \\
\text { Demographics }\end{array}$} & Age at Baseline $^{\mathrm{a}}$ & $24.3(4.1)$ \\
\hline & Verbal Memory - Immediate*b,c & $-1.3(1.4)[87]$ \\
\hline & Verbal Memory - Delayed*b,c & $-0.9(1.1)[87]$ \\
\hline & Education in Years* & $12.0(2.5)$ \\
\hline & Socioeconomic Status & $3.2(1.1)[81]$ \\
\hline & Performance IQ*b & $98.7(17.1)$ \\
\hline & Verbal IQ*b & $99.8(16.1)$ \\
\hline & Cumulative CPZ equivalent (in mg) & $4753.1(4770.7)$ \\
\hline & Adherence (\%) & $80(24)$ \\
\hline & $\begin{array}{l}\text { Duration Untreated Psychosis (weeks) } \\
\text { Duration Untreated Illness (years) }\end{array}$ & $\begin{array}{l}76.4(142.0) \\
\text { Median: } 20.1 \\
7.3(6.5) \\
\text { Median: } 6.1\end{array}$ \\
\hline & & Mean (SD) \\
\hline \multirow{5}{*}{$\begin{array}{c}\text { Baseline } \\
\text { Symptoms } \\
(\mathbf{N}=88)\end{array}$} & Amotivation & $11.3(6.1)$ \\
\hline & Expressivity & $7.1(7.2)$ \\
\hline & SAPS & $9.5(12.3)$ \\
\hline & CDSS & $2.4(2.9)$ \\
\hline & Window |Scan - Symptom Eval| (months) & $0.7(0.6)$ \\
\hline \multirow{5}{*}{$\begin{array}{l}\text { 1-year FUP } \\
\text { Symptoms } \\
(\mathbf{N}=\mathbf{8 0})\end{array}$} & Amotivation & $8.7(7.0)$ \\
\hline & Expressivity & $5.8(6.5)$ \\
\hline & SAPS & $7.9(10.2)$ \\
\hline & CDSS & $1.5(2.7)[79]$ \\
\hline & Window |Scan - Symptom Eval| (months) & $2.1(2.0)$ \\
\hline \multirow{5}{*}{$\begin{array}{l}\text { 2-year FUP } \\
\text { Symptoms } \\
\quad(N=65)\end{array}$} & Amotivation & $7.4(6.8)$ \\
\hline & Expressivity & $5.1(6.6)$ \\
\hline & SAPS & 7.9 (13.9) \\
\hline & CDSS & $1.9(2.6)[60]$ \\
\hline & Window |Scan - Symptom Eval| (months) & $0.6(1.2)$ \\
\hline
\end{tabular}

Statistic df p-value

$\mathrm{t}=-0.009 \quad 164.1 \quad 0.99$

$24.27(3.3)$

0.03 (1)

$0.02(0.8)$

$14.3(2.4)$

3.0 (1.0) [76]

106.9 (12.7)

110.0 (14.9)

$\mathrm{F}=23.38$

1,163

0.99

$<0.001$

$<0.001$

$<0.001$

0.34

0.001

$<0.001$

$\mathrm{U}=2447.50$

$\mathrm{U}=2345.50$

$\mathrm{U}=1887.00$

1,163

.

\section{Mean Difference Control-FEP}

$-0.005$

1.38

0.92

2.3

$-0.16$

8.15

10.16 


\section{Figure 1.}

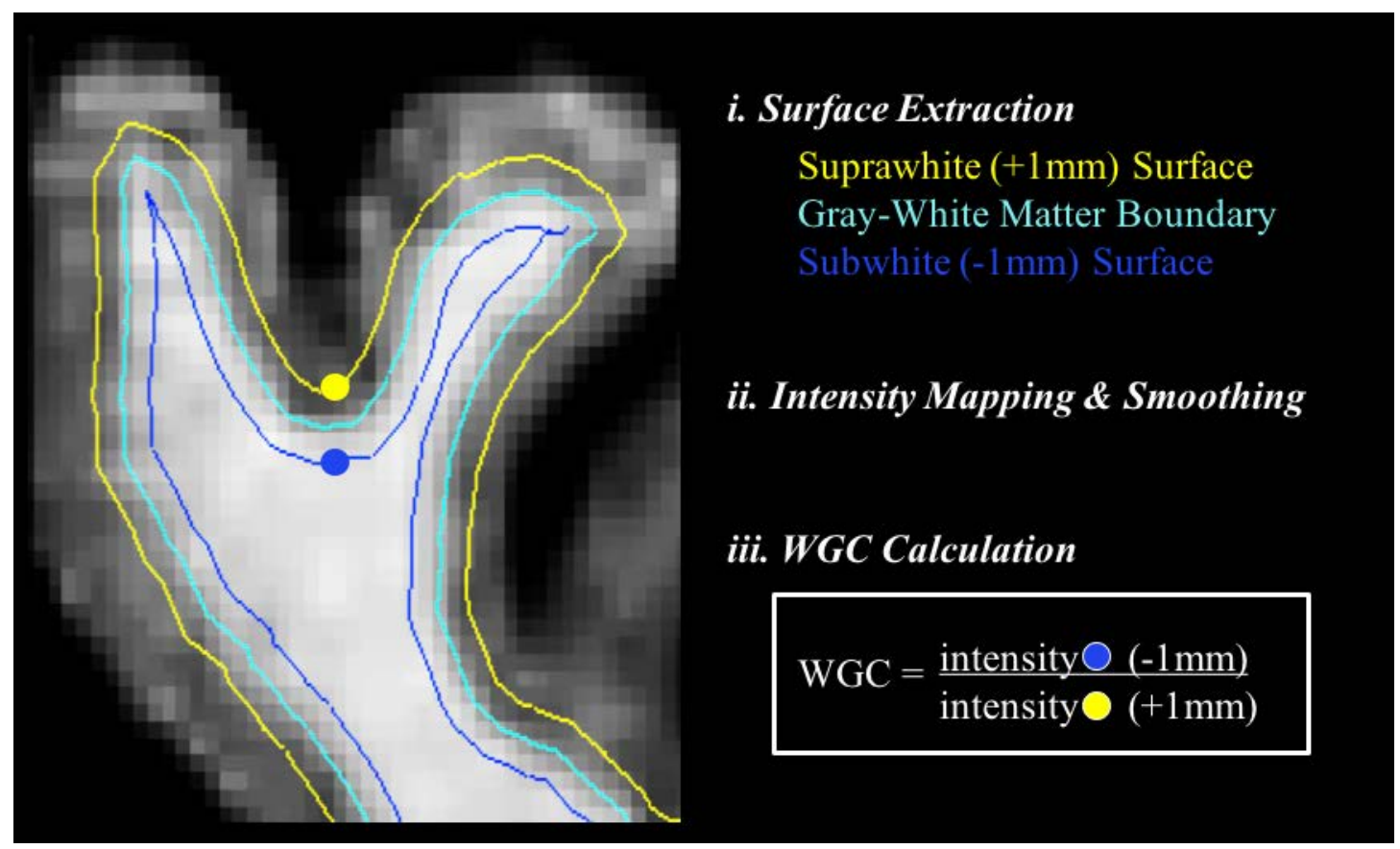


Makowski et al., Verbal Memory and Expressivity in Early Psychosis

Originally Published at 10.1017/s0033291719002071

\section{Figure 2}

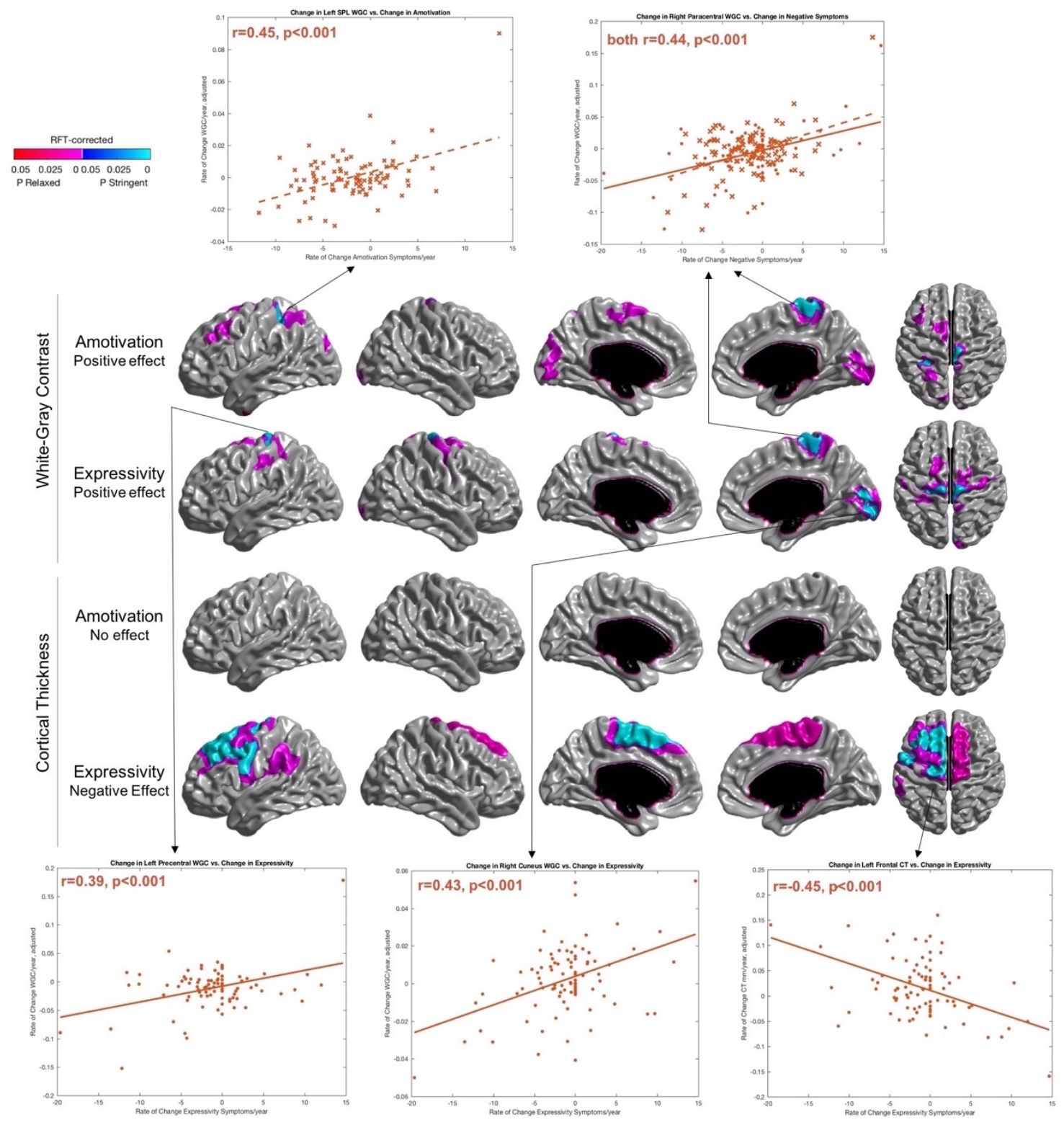


Makowski et al., Verbal Memory and Expressivity in Early Psychosis

Originally Published at 10.1017/s0033291719002071

Figure 3

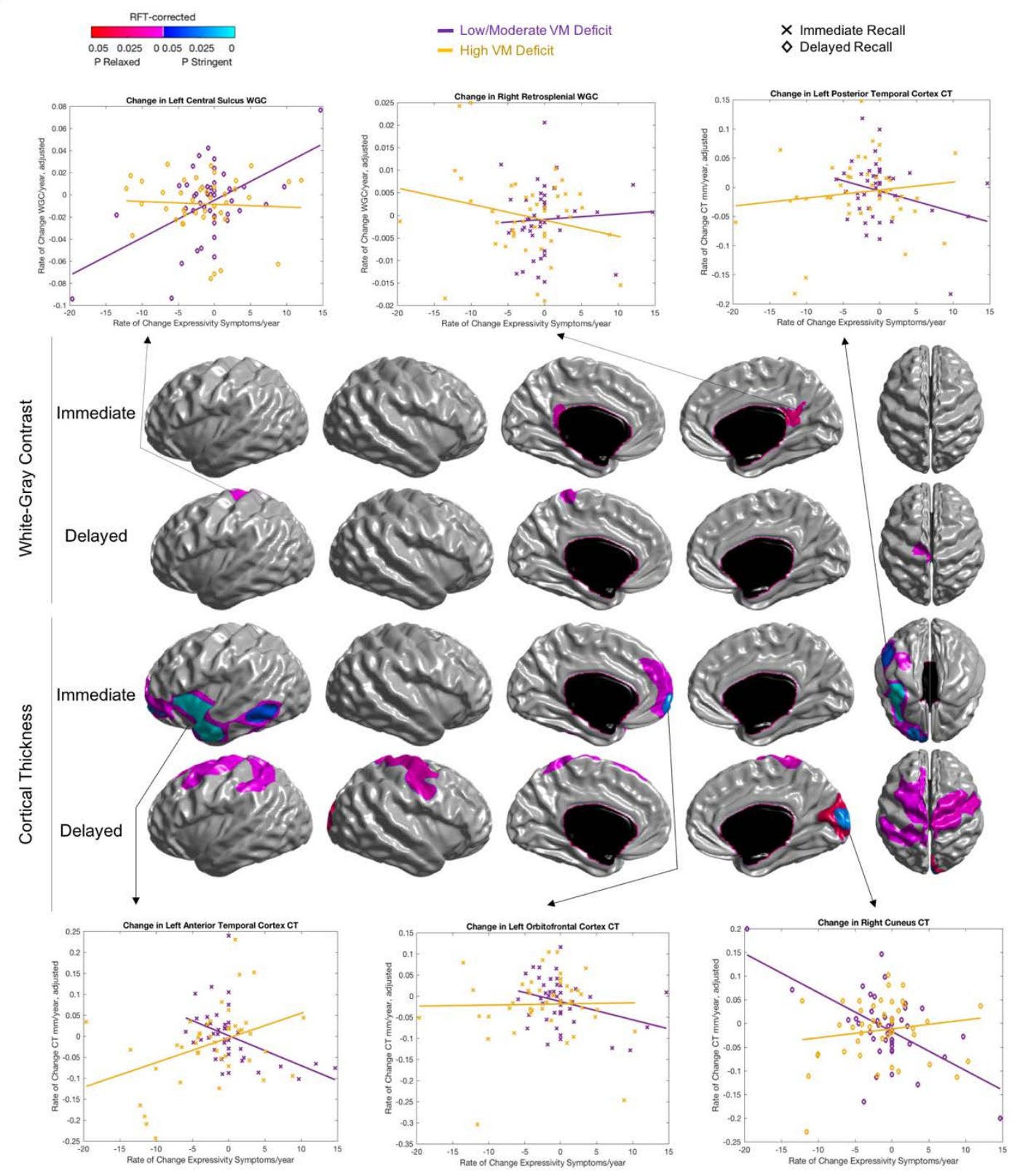


Makowski et al., Verbal Memory and Expressivity in Early Psychosis

Originally Published at 10.1017/s0033291719002071

\section{REFERENCES}

Abramovic L, Boks MPM, Vreeker A, Bouter DC, Kruiper C, Verkooijen S, Van Bergen AH, Ophoff RA, Kahn RS, Van Haren NEM (2016). The association of antipsychotic medication and lithium with brain measures in patients with bipolar disorder. European Neuropsychopharmacology 26, 1741-1751.

Akaike H (1998). Information theory and an extension of the maximum likelihood principle. In Selected Papers of Hirotugu Akaike, Springer Series in Statistics, pp199-213. Springer New York: New York, NY.

Albert N, Bertelsen M, Thorup A, Petersen L, Jeppesen P, Le Quack P, Krarup G, Jørgensen P, Nordentoft M (2011). Predictors of recovery from psychosis: Analyses of clinical and social factors associated with recovery among patients with first-episode psychosis after 5 years. Schizophrenia Research 125, 257-266.

Alexander MP, Stuss DT, Fansabedian N (2003). California Verbal Learning Test: performance by patients with focal frontal and non-frontal lesions. Brain 126, 1493-1503. Andreasen N (1984). Scale for the Assessment of Negative Symptoms (SANS). University of Iowa: Iowa City.

Andreasen NC, Ehrhardt JC, Swayze VW, Tyrrell G, Cohen G, Ku JS, Arndt S (1991). T1 and T2 relaxation times in schizophrenia as measured with magnetic resonance imaging. Schizophrenia Research 5, 223-32.

Andreasen NC, Nopoulos P, Magnotta V, Pierson R, Ziebell S, Ho B-C (2011). Progressive Brain Change in Schizophrenia: A Prospective Longitudinal Study of First-Episode Schizophrenia. Biological Psychiatry 70, 672-679.

Andrews DS, Avino TA, Gudbrandsen M, Daly E, Marquand A, Murphy CM, Lai M-C, Lombardo M V., Ruigrok ANV, Williams SC, Bullmore ET, The MRC AIMS Consortium TMA, Suckling J, Baron-Cohen S, Craig MC, Murphy DGM, Ecker C (2017). In Vivo Evidence of Reduced Integrity of the Gray-White Matter Boundary in Autism Spectrum Disorder. Cerebral Cortex 69, 63-70.

Asami T, Hyuk Lee S, Bouix S, Rathi Y, Whitford TJ, Niznikiewicz M, Nestor P, McCarley RW, Shenton ME, Kubicki M (2014). Cerebral white matter abnormalities and their associations with negative but not positive symptoms of schizophrenia. Psychiatry Research 222, 52-9.

Bartzokis G, Lu PH, Stewart SB, Oluwadara B, Lucas AJ, Pantages J, Pratt E, Sherin JE, Altshuler LL, Mintz J, Gitlin MJ, Subotnik KL, Nuechterlein KH (2009). In vivo evidence of differential impact of typical and atypical antipsychotics on intracortical myelin in adults with schizophrenia. Schizophrenia Research 113, 322-331.

Benjamini Y, Hochberg Y (1995). Controlling the false discovery rate: a practical and powerful approach to multiple testing. Journal of the Royal Statistical Society B 57, 289-300.

Benoit A, Malla AK, Iyer SN, Joober R, Bherer L, Lepage M (2015). Cognitive deficits characterization using the CogState Research Battery in first-episode psychosis patients. Schizophrenia Research: Cognition 2, 140-145.

Birur B, Kraguljac NV, Shelton RC, Lahti AC (2017). Brain structure, function, and neurochemistry in schizophrenia and bipolar disorder-a systematic review of the magnetic resonance neuroimaging literature. NPJ schizophrenia 3, 15.

Blanchard JJ, Cohen AS (2006). The Structure of Negative Symptoms Within Schizophrenia: Implications for Assessment. Schizophrenia Bulletin 32, 238-245. 
Makowski et al., Verbal Memory and Expressivity in Early Psychosis Originally Published at 10.1017/s0033291719002071

Boucher M, Whitesides S, Evans A (2009). Depth potential function for folding pattern representation, registration and analysis. Medical Image Analysis 13, 203-214.

Cantor-Graae E, Warkentin S, Nilsson A (1995). Neuropsychological assessment of schizophrenic patients during a psychotic episode: persistent cognitive deficit? Acta Psychiatrica Scandinavica 91, 283-288.

Carletti F, Woolley JB, Bhattacharyya S, Perez-Iglesias R, Fusar Poli P, Valmaggia L, Broome MR, Bramon E, Johns L, Giampietro V, Williams SCR, Barker GJ, McGuire PK (2012). Alterations in white matter evident before the onset of psychosis. Schizophrenia Bulletin 38, 1170-1179.

Carrión RE, McLaughlin D, Auther AM, Olsen R, Correll CU, Cornblatt BA (2015). The impact of psychosis on the course of cognition: a prospective, nested case-control study in individuals at clinical high-risk for psychosis. Psychological Medicine 45, 3341-54.

Charlton RA, Barrick TR, Markus HS, Morris RG (2013). Verbal working and long-term episodic memory associations with white matter microstructure in normal aging investigated using tract-based spatial statistics. Psychology and Aging 28, 768-777.

Cohen AS, Elvevåg B (2014). Automated computerized analysis of speech in psychiatric disorders. Current Opinion in Psychiatry 27, 203-9.

Cohen AS, Mitchell KR, Elvevåg B (2014). What do we really know about blunted vocal affect and alogia? A meta-analysis of objective assessments. Schizophrenia Research 159, 533-538.

Collins DL, Neelin P, Peters TM, Evans AC (1994). Automatic 3D intersubject Registration fo MR Volumetric Data in Standardized Talairach Space. Journal of Computer Assisted Tomography 18, 192-205.

Dazzan P, Arango C, Fleischacker W, Galderisi S, Glenthøj B, Leucht S, MeyerLindenberg A, Kahn R, Rujescu D, Sommer I, Winter I, McGuire P (2015). Magnetic resonance imaging and the prediction of outcome in first-episode schizophrenia: a review of current evidence and directions for future research. Schizophrenia Bulletin 41, 574-83. Friederici AD (2011). The brain basis of language processing: from structure to function. Physiological Reviews 91, 1357-92.

Galderisi S, Merlotti E, Mucci A (2015). Neurobiological background of negative symptoms. European Archives of Psychiatry and Clinical Neuroscience 265, 543-558.

Ganzetti M, Wenderoth N, Mantini D (2015). Mapping pathological changes in brain structure by combining T1- and T2-weighted MR imaging data. Neuroradiology 57, 917-28.

Glasser MF, Van Essen DC (2011). Mapping human cortical areas in vivo based on myelin content as revealed by T1- and T2-weighted MRI. The Journal of Neuroscience 31, 11597-616.

Goldberg TE, Torrey EF, Gold JM, Ragland JD, Bigelow LB, Weinberger DR (1993). Learning and memory in monozygotic twins discordant for schizophrenia. Psychological Medicine 23, 71-85.

Gong Q, Lui S, Sweeney JA (2016). A selective review of cerebral abnormalities in patients with first-episode schizophrenia before and after treatment. American Journal of Psychiatry 173, 232-243.

Green MF, Harvey PD (2014). Cognition in schizophrenia: Past, present, and future. Schizophrenia Research Cognition 1, 1-21.

Guimond S, Chakravarty MM, Bergeron-Gagnon L, Patel R, Lepage M (2016). Verbal memory impairments in schizophrenia associated with cortical thinning. NeuroImage: Clinical 11, 20-29.

Haber SN (2016). Corticostriatal circuitry. Dialogues in clinical neuroscience 18, 7-21. 
Hartmann-Riemer MN, Hager OM, Kirschner M, Bischof M, Kluge A, Seifritz E, Kaiser S (2015). The association of neurocognitive impairment with diminished expression and apathy in schizophrenia. Schizophrenia Research 169, 427-432.

Haukvik UK, Hartberg CB, Nerland S, Jørgensen KN, Lange EH, Simonsen C, Nesvåg R, Dale AM, Andreassen OA, Melle I, Agartz I (2016). No progressive brain changes during a 1year follow-up of patients with first-episode psychosis. Psychological Medicine 46, 589-598. Hoff AL, Sakuma M, Wieneke M, Horon R, Kushner M, DeLisi LE (1999). Longitudinal neuropsychological follow-up study of patients with first-episode schizophrenia. American Journal of Psychiatry 156, 1336-41.

Hovington CL, Bodnar M, Joober R, Malla AK, Lepage M (2013). Impairment in verbal memory observed in first episode psychosis patients with persistent negative symptoms. Schizophrenia Research 147, 223-229.

Insel T, Cuthbert B, Garvey M, Heinssen R, Pine DS, Quinn K, Sanislow C, Wang P (2010). Research Domain Criteria (RDoC): Toward a New Classification Framework for Research on Mental Disorders. American Journal of Psychiatry 167, 748-751.

Iwatani J, Ishida T, Donishi T, Ukai S, Shinosaki K, Terada M, Kaneoke Y (2015). Use of T1-weighted/T2-weighted magnetic resonance ratio images to elucidate changes in the schizophrenic brain. Brain and Behavior 5, e00399.

Iyer S, Jordan G, MacDonald K, Joober R, Malla A (2015). Early intervention for psychosis: a Canadian perspective. The Journal of Nervous and Mental Disease 203, 356-64.

Jang S-K, Choi H-I, Park S, Jaekal E, Lee G-Y, Cho Y Il, Choi K-H (2016). A Two-Factor Model Better Explains Heterogeneity in Negative Symptoms: Evidence from the Positive and Negative Syndrome Scale. Frontiers in Psychology 7, 707.

Jones SE, Buchbinder BR, Aharon I (2000). Three-dimensional mapping of cortical thickness using Laplace's equation. Human Brain Mapping 11, 12-32.

Jordan G, Lutgens D, Joober R, Lepage M, Iyer SN, Malla A (2014). The Relative Contribution of Cognition and Symptomatic Remission to Functional Outcome Following Treatment of a First Episode of Psychosis. The Journal of Clinical Psychiatry 75, e566-e572. Jordan G, Veru F, Lepage M, Joober R, Malla A, Iyer SN (2018). Pathways to functional outcomes following a first episode of psychosis: The roles of premorbid adjustment, verbal memory and symptom remission. Australian \& New Zealand Journal of Psychiatry 52, 793-803. June SK, Singh V, Jun KL, Lerch J, Ad-Dab'bagh Y, MacDonald D, Jong ML, Kim SI, Evans AC (2005). Automated 3-D extraction and evaluation of the inner and outer cortical surfaces using a Laplacian map and partial volume effect classification. NeuroImage 27, 210221.

Kelly S, Jahanshad N, Zalesky A, Kochunov P, Agartz I, Alloza C, Andreassen OA, Arango C, Banaj N, Bouix S, Bousman CA, Brouwer RM, Bruggemann J, Bustillo J, Cahn W, Calhoun V, Cannon D, Carr V, Catts S, Chen J, Chen J, Chen X, Chiapponi C, Cho KK, Ciullo V, Corvin AS, Crespo-Facorro B, Cropley V, De Rossi P, Diaz-Caneja CM, Dickie EW, Ehrlich S, Fan F, Faskowitz J, Fatouros-Bergman H, Flyckt L, Ford JM, Fouche J-P, Fukunaga M, Gill M, Glahn DC, Gollub R, Goudzwaard ED, Guo H, Gur RE, Gur RC, Gurholt TP, Hashimoto R, Hatton SN, Henskens FA, Hibar DP, Hickie IB, Hong LE, Horacek J, Howells FM, Hulshoff Pol HE, Hyde CL, Isaev D, Jablensky A, Jansen PR, Janssen J, Jönsson EG, Jung LA, Kahn RS, Kikinis Z, Liu K, Klauser P, Knöchel C, Kubicki M, Lagopoulos J, Langen C, Lawrie S, Lenroot RK, Lim KO, Lopez-Jaramillo C, Lyall A, Magnotta V, Mandl RCW, Mathalon DH, McCarley RW, McCarthy-Jones S, 
McDonald C, McEwen S, McIntosh A, Melicher T, Mesholam-Gately RI, Michie PT, Mowry B, Mueller BA, Newell DT, O'Donnell P, Oertel-Knöchel V, Oestreich L, Paciga SA, Pantelis C, Pasternak O, Pearlson G, Pellicano GR, et al. (2018). Widespread white matter microstructural differences in schizophrenia across 4322 individuals: results from the ENIGMA Schizophrenia DTI Working Group. Molecular Psychiatry 23, 1261-1269.

Kim JS, Singh V, Lee JK, Lerch J, Ad-Dab'bagh Y, MacDonald D, Lee JM, Kim SI, Evans AC (2005). Automated 3-D extraction and evaluation of the inner and outer cortical surfaces using a Laplacian map and partial volume effect classification. NeuroImage 27, 210-221.

Kirkpatrick B, Fenton WS, Carpenter WT, Marder SR (2006). The NIMH-MATRICS consensus statement on negative symptoms. Schizophrenia Bulletin 32, 214-219.

Klauser P, Baker ST, Cropley VL, Bousman C, Fornito A, Cocchi L, Fullerton JM, Rasser P, Schall U, Henskens F, Michie PT, Loughland C, Catts S V, Mowry B, Weickert TW, Shannon Weickert C, Carr V, Lenroot R, Pantelis C, Zalesky A (2017). White Matter Disruptions in Schizophrenia Are Spatially Widespread and Topologically Converge on Brain Network Hubs. Schizophrenia Bulletin 43, 425-435.

Kubicki M, Park H, Westin CF, Nestor PG, Mulkern R V., Maier SE, Niznikiewicz M, Connor EE, Levitt JJ, Frumin M, Kikinis R, Jolesz FA, McCarley RW, Shenton ME (2005). DTI and MTR abnormalities in schizophrenia: Analysis of white matter integrity. NeuroImage 26, 1109-1118.

Lake EMR, Steffler EA, Rowley CD, Sehmbi M, Minuzzi L, Frey BN, Bock NA (2017). Altered intracortical myelin staining in the dorsolateral prefrontal cortex in severe mental illness. European Archives of Psychiatry and Clinical Neuroscience 267, 369-376.

Lang DJM, Yip E, MacKay AL, Thornton AE, Vila-Rodriguez F, MacEwan GW, Kopala LC, Smith GN, Laule C, MacRae CB, Honer WG (2014). 48 echo $\mathrm{T}_{2}$ myelin imaging of white matter in first-episode schizophrenia: evidence for aberrant myelination. NeuroImage. Clinical $\mathbf{6}$, 408-14.

Lee S-H, Kubicki M, Asami T, Seidman LJ, Goldstein JM, Mesholam-Gately RI, McCarley RW, Shenton ME (2013). Extensive white matter abnormalities in patients with first-episode schizophrenia: a Diffusion Tensor Imaging (DTI) study. Schizophrenia Research 143, 231-8. Leeson VC, Robbins TW, Franklin C, Harrison M, Harrison I, Ron MA, Barnes TRE, Joyce EM (2009). Dissociation of long-term verbal memory and fronto-executive impairment in first-episode psychosis. Psychological Medicine 39, 1799.

Lepage M, Bodnar M, Bowie CR (2014). Neurocognition: clinical and functional outcomes in schizophrenia. Canadian Journal of Psychiatry 59, 5-12.

Lepage M, Buchy L, Bodnar M, Bertrand M-C, Joober R, Malla A (2008). Cognitive insight and verbal memory in first episode of psychosis. European Psychiatry 23, 368-374.

Lerch JP, Evans AC (2005). Cortical thickness analysis examined through power analysis and a population simulation. NeuroImage 24, 163-173.

Lewis JD, Evans AC, Tohka J (2018). T1 white/gray contrast as a predictor of chronological age, and an index of cognitive performance. NeuroImage 173, 341-450.

Lindgren M, Manninen M, Kalska H, Mustonen U, Laajasalo T, Moilanen K, Huttunen MO, Cannon TD, Therman S, Suvisaari J (2017). Evaluation of verbal list learning as a predictor of psychosis. Early Intervention in Psychiatry 11, 171-176.

Lutgens D, Iyer S, Joober R, Schmitz N, Lepage M, Mustafa S, Malla A (2019). Progress of Negative Symptoms during the Critical Period of the First Five Years of a First Episode of Psychosis. Psychological Medicine 49, 66-74. 
Makowski et al., Verbal Memory and Expressivity in Early Psychosis

Originally Published at 10.1017/s0033291719002071

Lutgens D, Lepage M, Iyer S, Malla A (2014). Predictors of cognition in first episode psychosis. Schizophrenia Research 152, 164-169.

Lysaker PH, Carcione A, Dimaggio G, Johannesen JK, Nicolo G, Procacci M, Semerari A (2005). Metacognition amidst narratives of self and illness in schizophrenia: associations with neurocognition, symptoms, insight and quality of life. Acta Psychiatrica Scandinavica 112, 6471.

Lyttelton O, Boucher M, Robbins S, Evans A (2007). An unbiased iterative group registration template for cortical surface analysis. NeuroImage 34, 1535-1544.

MacDonald K, Malla A, Joober R, Shah JL, Goldberg K, Abadi S, Doyle M, Iyer SN (2018). Description, evaluation and scale-up potential of a model for rapid access to early intervention for psychosis. Early Intervention in Psychiatry 12, 1222-1228.

Makowski C, Bodnar M, Malla AK, Joober R, Lepage M (2016). Age-related cortical thickness trajectories in first episode psychosis patients presenting with early persistent negative symptoms. npj Schizophrenia 2, 16029.

Makowski C, Bodnar M, Shenker JJ, Malla AK, Joober R, Chakravarty MM, Lepage M (2017). Linking persistent negative symptoms to amygdala-hippocampus structure in firstepisode psychosis. Translational Psychiatry 7, e1195.

Makowski C, Lewis JD, Lepage C, Malla AK, Joober R, Lepage M, Evans AC (2019). Structural Associations in First Episode Psychosis Using Cortical Contrast and Cortical Thickness. Cerebral Cortex Accepted

Malla AK, Takhar JJ, Norman RMG, Manchanda R, Cortese L, Haricharan R, Verdi M, Ahmed R (2002). Negative symptoms in first episode non-affective psychosis. Acta Psychiatrica Scandinavica 105, 431-439.

Marder SR, Galderisi S (2017). The current conceptualization of negative symptoms in schizophrenia. World Psychiatry 16, 14-24.

Messinger JW, Trémeau F, Antonius D, Mendelsohn E, Prudent V, Stanford AD, Malaspina D (2011). Avolition and expressive deficits capture negative symptom phenomenology: Implications for DSM-5 and schizophrenia research. Clinical Psychology Review 31, 161-168.

Millan MJ, Fone K, Steckler T, Horan WP (2014). Negative symptoms of schizophrenia: clinical characteristics, pathophysiological substrates, experimental models and prospects for improved treatment. European Neuropsychopharmacology 24, 645-92.

Mitelman SA, Shihabuddin L, Brickman AM, Hazlett EA, Buchsbaum MS (2005). Volume of the cingulate and outcome in schizophrenia. Schizophrenia Research 72, 91-108.

Mørch-Johnsen L, Agartz I, Jensen J (2018). The Neural Correlates of Negative Symptoms in Schizophrenia: Examples From MRI Literature. Clinical EEG and Neuroscience 49, 12-17.

Mørch-Johnsen L, Nesvåg R, Faerden A, Haukvik UK, Jørgensen KN, Lange EH, Andreassen OA, Melle I, Agartz I (2015). Brain structure abnormalities in first-episode psychosis patients with persistent apathy. Schizophrenia Research 164, 59-64.

Nesvåg R, Bergmann Ø, Rimol LM, Lange EH, Haukvik UK, Hartberg CB, Fagerberg T, Söderman E, Jönsson EG, Agartz I (2012). A 5-year follow-up study of brain cortical and subcortical abnormalities in a schizophrenia cohort. Schizophrenia Research 142, 209-216. Nopoulos P, Flashman L, Flaum M, Arndt S, Andreasen N (1994). Stability of cognitive functioning early in the course of schizophrenia. Schizophrenia Research 14, 29-37.

Ochoa S, Usall J, Cobo J, Labad X, Kulkarni J (2012). Gender Differences in Schizophrenia and First-Episode Psychosis: A Comprehensive Literature Review. Schizophrenia Research and 
Makowski et al., Verbal Memory and Expressivity in Early Psychosis

Originally Published at 10.1017/s0033291719002071

Treatment 2012, 1-9.

Ohtani T, Bouix S, Hosokawa T, Saito Y, Eckbo R, Ballinger T, Rausch A, Melonakos E, Kubicki M (2014). Abnormalities in white matter connections between orbitofrontal cortex and anterior cingulate cortex and their associations with negative symptoms in schizophrenia: A DTI study. Schizophrenia Research 157, 190-197.

Ohtani T, Bouix S, Lyall AE, Hosokawa T, Saito Y, Melonakos E, Westin CF, Seidman LJ, Goldstein J, Mesholam-Gately R, Petryshen T, Wojcik J, Kubicki M (2015). Abnormal

white matter connections between medial frontal regions predict symptoms in patients with first episode schizophrenia. Cortex 71, 264-276.

Owen M (2018). 9. Does Biology Read the DSM? Transdiagnostic Findings in Psychosis And Implications For Treatment. Schizophrenia Bulletin 44, S12-S13.

Pietrzak RH, Olver J, Norman T, Piskulic D, Maruff P, Snyder PJ (2009). A comparison of the CogState Schizophrenia Battery and the Measurement and Treatment Research to Improve Cognition in Schizophrenia (MATRICS) Battery in assessing cognitive impairment in chronic schizophrenia. Journal of Clinical and Experimental Neuropsychology 31, 848-859.

Radua J, Borgwardt S, Crescini A, Mataix-Cols D, Meyer-Lindenberg A, McGuire PK, Fusar-Poli P (2012). Multimodal meta-analysis of structural and functional brain changes in first episode psychosis and the effects of antipsychotic medication. Neuroscience \& Biobehavioral Reviews 36, 2325-2333.

Raznahan A, Lerch JP, Lee N, Greenstein D, Wallace GL, Stockman M, Clasen L, Shaw PW, Giedd JN (2011). Patterns of coordinated anatomical change in human cortical development: A longitudinal neuroimaging study of maturational coupling. Neuron 72, 873-884. Roiz-Santiáñez R, Ortiz-García de la Foz V, Ayesa-Arriola R, Tordesillas-Gutiérrez D, Jorge R, Varela-Gómez N, Suárez-Pinilla P, Córdova-Palomera A, Navasa-Melado JM, Crespo-Facorro B (2015). No progression of the alterations in the cortical thickness of individuals with schizophrenia-spectrum disorder: a three-year longitudinal magnetic resonance imaging study of first-episode patients. Psychological Medicine 45, 2861-2871.

Salat DH, Lee SY, van der Kouwe AJ, Greve DN, Fischl B, Rosas HD (2009). Ageassociated alterations in cortical gray and white matter signal intensity and gray to white matter contrast. NeuroImage 48, 21-28.

Saur D, Kreher BW, Schnell S, Kümmerer D, Kellmeyer P, Vry M-S, Umarova R, Musso M, Glauche V, Abel S, Huber W, Rijntjes M, Hennig J, Weiller C (2008). Ventral and dorsal pathways for language. Proceedings of the National Academy of Sciences of the United States of America 105, 18035-40.

Sigmundsson T, Suckling J, Maier M, Williams SCR, Bullmore ET, Greenwood KE, Fukuda R, Ron MA, Toone BK (2001). Structural Abnormalities in Frontal, Temporal, and Limbic Regions and Interconnecting White Matter Tracts in Schizophrenic Patients With Prominent Negative Symptoms. American Journal of Psychiatry 158, 234-243.

Sled JG, Zijdenbos AP, Evans AC (1998). A nonparametric method for automatic correction of intensity nonuniformity in MRI data. IEEE transactions on medical imaging 17, 87-97.

Smith DM, Barredo J, Mizumori SJY (2012). Complimentary roles of the hippocampus and retrosplenial cortex in behavioral context discrimination. Hippocampus 22, 1121-1133.

Smith DM, Miller AMP, Vedder LC (2018). The retrosplenial cortical role in encoding behaviorally significant cues. Behavioral Neuroscience 132, 356-365.

Smith EE, Jonides J (1999). Storage and executive processes in the frontal lobes. Science 283, 1657-61. 
Makowski et al., Verbal Memory and Expressivity in Early Psychosis

Originally Published at 10.1017/s0033291719002071

Strauss GP, Nuñez A, Ahmed AO, Barchard KA, Granholm E, Kirkpatrick B, Gold JM, Allen DN (2018). The Latent Structure of Negative Symptoms in Schizophrenia. JAMA Psychiatry

Szeszko PR, Robinson DG, Ikuta T, Peters BD, Gallego JA, Kane J, Malhotra AK (2014). White matter changes associated with antipsychotic treatment in first-episode psychosis. Neuropsychopharmacology 39, 1324-31.

Tamnes CK, Østby Y, Fjell AM, Westlye LT, Due-Tønnessen P, Walhovd KB (2010). Brain Maturation in Adolescence and Young Adulthood: Regional Age-Related Changes in Cortical Thickness and White Matter Volume and Microstructure. Cerebral Cortex 20, 534-548.

Tohka J, Zijdenbos A, Evans A (2004). Fast and robust parameter estimation for statistical partial volume models in brain MRI. NeuroImage 23, 84-97.

Turetsky B, Cowell PE, Gur RC, Grossman RI, Shtasel DL, Gur RE (1995). Frontal and Temporal Lobe Brain Volumes in Schizophrenia. Archives of General Psychiatry 52, 1061. Uranova NA, Vikhreva O V., Rachmanova VI, Orlovskaya DD (2011). Ultrastructural Alterations of Myelinated Fibers and Oligodendrocytes in the Prefrontal Cortex in Schizophrenia: A Postmortem Morphometric Study. Schizophrenia Research and Treatment 2011, 1-13.

Vann SD, Aggleton JP, Maguire EA (2009). What does the retrosplenial cortex do? Nature Reviews Neuroscience 10, 792-802.

Vita A, De Peri L, Deste G, Sacchetti E (2012). Progressive loss of cortical gray matter in schizophrenia: a meta-analysis and meta-regression of longitudinal MRI studies. Translational Psychiatry 2, e190.

Wagstyl K, Ronan L, Whitaker KJ, Goodyer IM, Roberts N, Crow TJ, Fletcher PC (2016). Multiple markers of cortical morphology reveal evidence of supragranular thinning in schizophrenia. Translational Psychiatry 6, e780.

Walton E, Hibar DP, van Erp TGM, Potkin SG, Roiz-Santiañez R, Crespo-Facorro B, Suarez-Pinilla P, van Haren NEM, de Zwarte SMC, Kahn RS, Cahn W, Doan NT, Jørgensen KN, Gurholt TP, Agartz I, Andreassen OA, Westlye LT, Melle I, Berg AO, Morch-Johnsen L, Færden A, Flyckt L, Fatouros-Bergman H, Jönsson EG, Hashimoto R, Yamamori H, Fukunaga M, Jahanshad N, De Rossi P, Piras F, Banaj N, Spalletta G, Gur RE, Gur RC, Wolf DH, Satterthwaite TD, Beard LM, Sommer IE, Koops S, Gruber O, Richter A, Krämer B, Kelly S, Donohoe G, McDonald C, Cannon DM, Corvin A, Gill M, Di Giorgio A, Bertolino A, Lawrie S, Nickson T, Whalley HC, Neilson E, Calhoun VD, Thompson PM, Turner JA, Ehrlich S, Ehrlich S, Karolinska Schizophrenia Project consortium (KaSP) (2017). Prefrontal cortical thinning links to negative symptoms in schizophrenia via the ENIGMA consortium. Psychological Medicine, 1-13.

Wechsler D (1997). Weschler Memory Scale (3rd ed). The Psychological Corporation: New York.

Wenger E, Brozzoli C, Lindenberger U, Lövdén M (2017). Expansion and Renormalization of Human Brain Structure During Skill Acquisition. Trends in Cognitive Sciences 21, 930-939. Westlye LT, Walhovd KB, Dale AM, Espeseth T, Reinvang I, Raz N, Agartz I, Greve DN, Fischl B, Fjell AM (2009). Increased sensitivity to effects of normal aging and Alzheimer's disease on cortical thickness by adjustment for local variability in gray/white contrast: A multisample MRI study. NeuroImage 47, 1545-1557.

Whitford TJ, Ford JM, Mathalon DH, Kubicki M, Shenton ME (2012). Schizophrenia, myelination, and delayed corollary discharges: a hypothesis. Schizophrenia Bulletin 38, 486-94. 
Whitford TJ, Grieve SM, Farrow TFD, Gomes L, Brennan J, Harris AWF, Gordon E, Williams LM (2007). Volumetric White Matter Abnormalities in First-Episode Schizophrenia: A Longitudinal, Tensor-Based Morphometry Study. American Journal of Psychiatry 164, 10821089.

Wible CG, Anderson J, Shenton ME, Kricun A, Hirayasu Y, Tanaka S, Levitt JJ, O’Donnell BF, Kikinis R, Jolesz FA, McCarley RW (2001). Prefrontal cortex, negative symptoms, and schizophrenia: an MRI study. Psychiatry Research 108, 65-78.

Wolfers T, Doan NT, Kaufmann T, Alnæs D, Moberget T, Agartz I, Buitelaar JK, Ueland T, Melle I, Franke B, Andreassen OA, Beckmann CF, Westlye LT, Marquand AF (2018). Mapping the Heterogeneous Phenotype of Schizophrenia and Bipolar Disorder Using Normative Models. JAMA Psychiatry

Worsley KJ, Taylor JE, Tomaiuolo F, Lerch J (2004). Unified univariate and multivariate random field theory. NeuroImage 23, S189-S195.

Zijdenbos AP, Forghani R, Evans AC (2002). Automatic 'pipeline' analysis of 3-D MRI data for clinical trials: application to multiple sclerosis. IEEE Transactions on Medical Imaging 21, 1280-1291. 